This article was downloaded by: [Ingenta Content Distribution TandF titles]

On: 4 November 2008

Access details: Access Details: [subscription number 791939330]

Publisher Taylor \& Francis

Informa Ltd Registered in England and Wales Registered Number: 1072954 Registered office: Mortimer House, 37-41 Mortimer Street, London W1T 3JH, UK

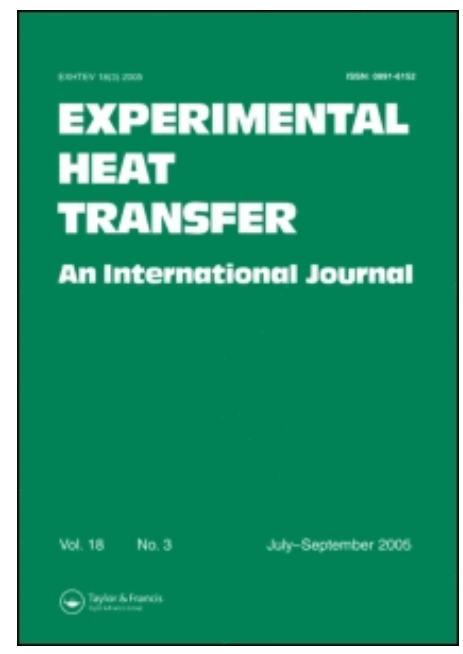

\title{
Experimental Heat Transfer
}

Publication details, including instructions for authors and subscription information:

http://www.informaworld.com/smpp/title content=t713770473

\section{CHARGE AND DISCHARGE CHARACTERISTICS OF A THERMAL ENERGY STORAGE DEVICE}

Jung-Chang Wang a; Shu-Ju Lin a; Sih-Li Chen a; Wen-Shing Lee ${ }^{b}$

a Department of Mechanical Engineering, National Taiwan University, Taipei, Taiwan ${ }^{\mathrm{b}}$ Department of Air-

conditioning and Refrigeration Engineering, National Taipei University of Technology, Taipei, Taiwan

Online Publication Date: 14 January 2005

To cite this Article Wang, Jung-Chang, Lin, Shu-Ju, Chen, Sih-Li and Lee, Wen-Shing(2005)'CHARGE AND DISCHARGE CHARACTERISTICS OF A THERMAL ENERGY STORAGE DEVICE',Experimental Heat Transfer, 18:1,45 — 60

To link to this Article: DOI: $10.1080 / 08916150590884844$

URL: http://dx.doi.org/10.1080/08916150590884844

\section{PLEASE SCROLL DOWN FOR ARTICLE}

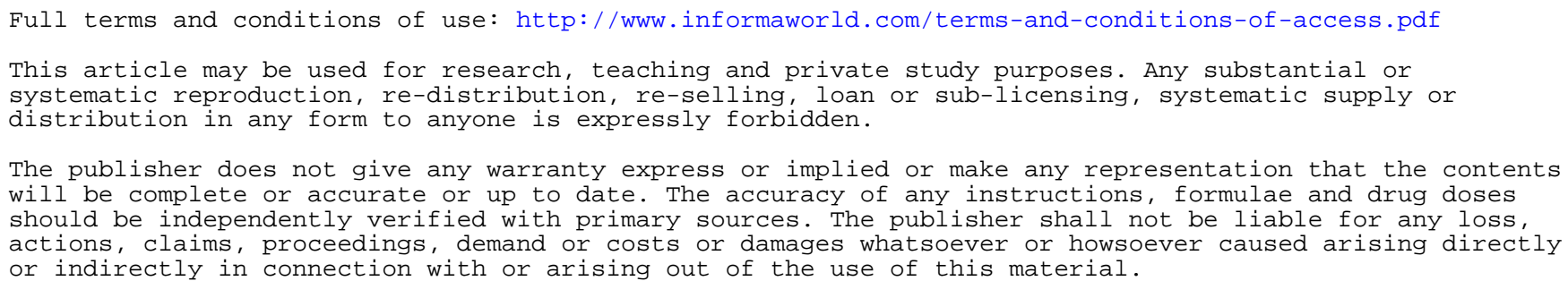




\title{
CHARGE AND DISCHARGE CHARACTERISTICS OF A THERMAL ENERGY STORAGE DEVICE
}

\section{Jung-Chang Wang, Shu-Ju Lin, and Sih-Li Chen}

National Taiwan University, Department of Mechanical Engineering,

Taipei, Taiwan

\section{Wen-Shing Lee}

National Taipei University of Technology, Department of Air-conditioning and Refrigeration Engineering, Taipei, Taiwan

\begin{abstract}
This article describes an experimental investigation on the thermal characteristics of a thermal energy storage device. It utilizes the superior heat transfer characteristics of wickless heat pipes and eliminates drawbacks found in the conventional thermal storage tank. This study purports to examine the functions of a thermal energy storage device having three operating modes, i.e., charge, discharge, and simultaneous charge and discharge. Different heat transfer mechanisms are identified in the thermal energy storage device under different operating modes. The thermal performance with alcohol and water as working fluid are also explored in the thermal energy storage device. The results show that a thermal energy storage device employing alcohol as the working fluid provides better performance. The system gives optimum charge and discharge performance under $35 \%-40 \%$ fill ratio and displays optimum charge efficiency of $73 \%$ and optimum discharge efficiency of $85 \%$.

Keywords thermal energy storage, wick-less, heat pipe,working fluid
\end{abstract}

\section{INTRODUCTION}

A number of thermal energy storage systems have been considered and developed in recent years [1-8]. Most of the energy storage systems utilize an active control method to store or release thermal energy. That is, in the system design of thermal storage, a pump is included to transfer thermal energy from a high temperature heat source to the thermal storage tank via flowing working fluid. To utilize the stored thermal energy, an electromagnetic valve is used under control to change flow path of the working fluid, so that energy stored in the storage tank is released to and used by a low temperature heat sink. There are two drawbacks found in such a type of thermal storage systems. First, the need of an operation cost and power consumption of pump. The thermal storage shall be unworkable in case of a system failure. Second, change of the charge and discharge ability of the conventional storage systems is basically reliant on the system piping design

Received 12 February 2003; accepted 12 April 2004.

Address correspondence to Sih-Li Chen, National Taiwan University, Department of Mechanical Engineering, 10673, Taipei, Taiwan, China. E-mail: slchenol@ccms.ntu.edu.tw 


\begin{tabular}{|c|c|c|c|}
\hline \multicolumn{4}{|c|}{ NOMENCLATURE } \\
\hline$A$ & area $\left[\mathrm{m}^{2}\right]$ & $T_{i n}$ & water inlet temperature $[\mathrm{K}]$ \\
\hline$c$ & specific heat $[\mathrm{J} / \mathrm{kg}-\mathrm{K}]$ & $T_{\text {out }}$ & water outlet temperature $[\mathrm{K}]$ \\
\hline$c_{p}$ & specific heat at constant pressure & & time $[\mathrm{sec}]$ \\
\hline & {$[\mathrm{J} / \mathrm{kg}-\mathrm{K}]$} & & operating time $[\mathrm{sec}]$ \\
\hline$L$ & length $[\mathrm{m}]$ & $V_{r}$ & actual volume of working fluid charged \\
\hline M & mass $[\mathrm{kg}]$ & & {$[\mathrm{ml}]$} \\
\hline$\dot{m}$ & mass rate $[\mathrm{kg} / \mathrm{s}]$ & $V_{t}$ & total volume of thermosyphon heat pipe \\
\hline$P$ & power $[\mathrm{W}]$ & & {$[\mathrm{ml}]$} \\
\hline$Q_{c}$ & released heat at condensation side $[\mathrm{J}]$ & & \\
\hline$Q_{c h}$ & heat storage $[\mathrm{J}]$ & \multicolumn{2}{|c|}{ Greek Symbols } \\
\hline$Q_{e f f}$ & effective heat $[\mathrm{J}]$ & $\Delta$ & variation of time \\
\hline$Q_{d i s}$ & discharge heat $[\mathrm{J}]$ & & \\
\hline$Q_{\text {in }}$ & heat supply $[\mathrm{J}]$ & \multicolumn{2}{|c|}{ Subscripts } \\
\hline$Q_{\text {sys }}$ & heat storage of system [J] & $i$ & count term \\
\hline$R$ & thermal resistance $[\mathrm{K} / \mathrm{W}]$ & $j$ & time term \\
\hline
\end{tabular}

and therefore only two functions, i.e., energy storage and energy release, are available in its operating modes. Due to an electromagnetic valve used under control to change flow path of the working fluid to store/use thermal heat to/from storage tank, it is impossible for both the heat supply and heat utilization sides of the thermal storage to operate at the same time during the energy utilization.

The objective of the present article is to provide a thermal energy storage device in which a passive type of control is adopted to eliminate drawbacks found in the conventional thermal storage systems and no pump and electromagnetic valve are required. Moreover, apart from storing and releasing energy, the thermal energy storage device also allows operation of a thermal energy supply side and thermal energy use side at the same time. During the thermal energy utilization, when extra thermal energy that is more than the amount needed by the thermal energy use side has been provided by the heat supply side, the heat not used by the thermal energy use side may be stored in the thermal energy storage device. Furthermore, when the thermal energy provided by the heat supply side is insufficient for use by the thermal energy use side, additional heat may be supplemented by the thermal energy storage device.

The thermal energy storage device, as shown in Figure 1, predominately includes the energy storage tank and the loop thermosyphon. The energy storage tank is filled with energy storage material, so that thermal energy can be stored or released via melting or freezing of the phase change medium between solid and liquid states. The heat pipe loops include three parts, namely, a group of parallel fin tubes vertically disposed inside the energy storage tank, the vertical high-temperature plate tubes located outside of the tank, and a horizontal low-temperature double pipe heat exchanger situated in the upper region inside the storage tank. The upper headers also work as a double pipe heat exchanger during heat release. An adequate amount of working fluid is filled in the loop thermosyphon. The parallel fin tubes combine the high-temperature vertical plate tubes to form a two-phase closed loop thermosyphon for thermal storage. The thermal release process is constructed by connecting the parallel fin tubes and the double pipe heat exchanger to form a two-phase closed thermosyphon. 


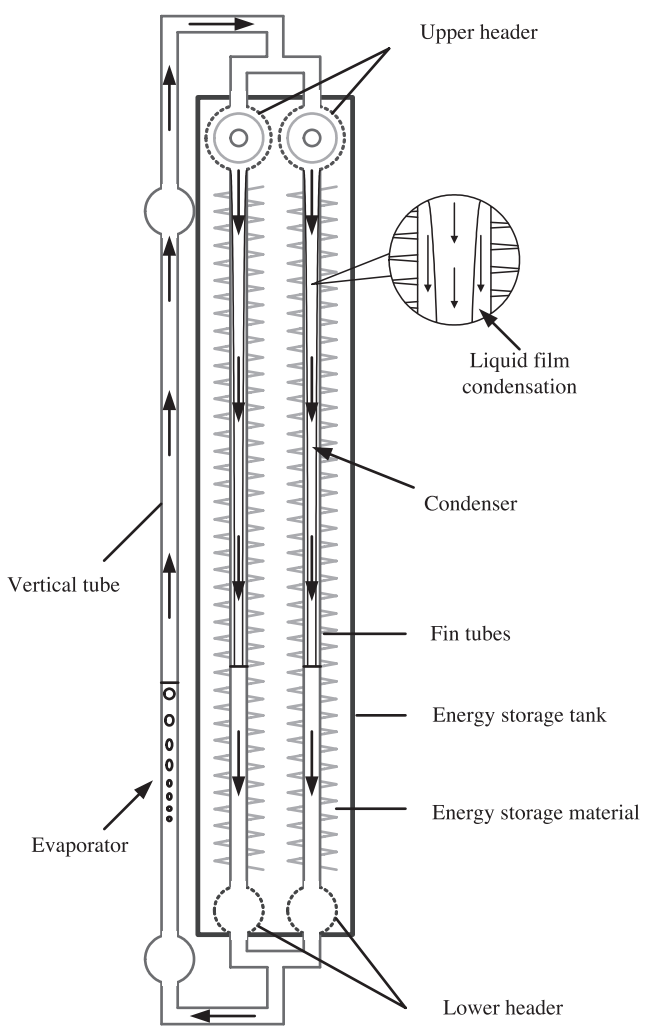

(a)

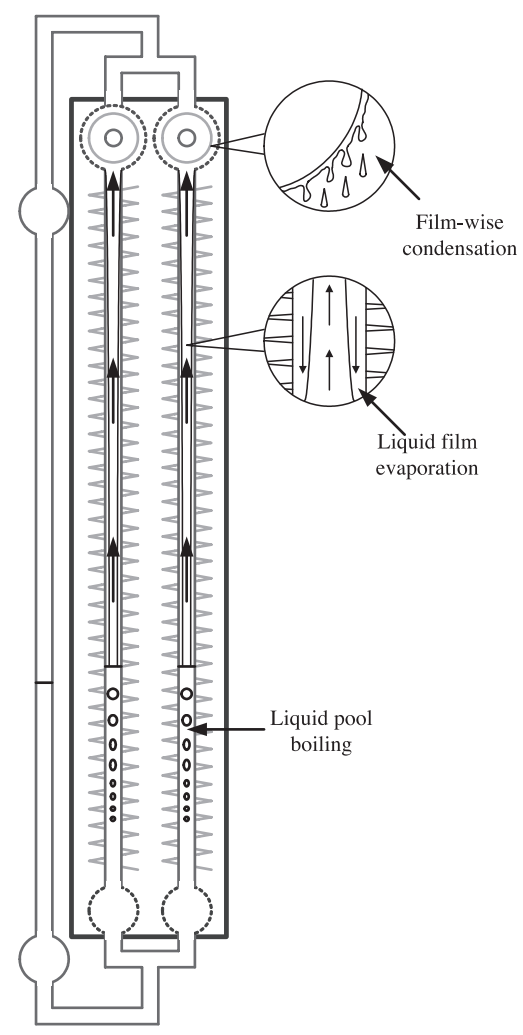

(b)

Figure 1. Thermal energy storage device system: (a) charge mode; (b) discharge mode.

Figure 1a shows the function in which the thermal energy storage device operates to store thermal energy. The working fluid inside the vertical high-temperature plate tubes having absorbed heat, becomes boiled and produces a gaseous working fluid which flows upward due to its buoyancy into the upper header and then downward into the vertically paralleled fin tubes in the energy storage tank. The vapor working fluid condenses and releases heat to melt solid phase change medium into liquid medium in the energy storing cells outside the parallel fin tubes. Since the condensed liquid working fluid has a density much larger than that of the vapor working fluid, it flows downward along inner wall surfaces of the vertical tubes under gravity and into the lower header and then the vertical high-temperature tubes to complete one cycle of flow. The thermal energy storage device absorbs heat through the evaporation of the working fluid inside vertical plate tubes and its condensation inside the parallel fin tubes.

Figure $1 \mathrm{~b}$ shows the manner in which the thermal energy storage device operates to release thermal energy. When the transporting fluid (i.e., cold water) enters the inside tube of the low-temperature double pipe heat exchanger, the energy storage material inside the tank will release heat. The released heat from the energy storage material causes the working fluid inside the vertical tubes to vaporize. At this point, the liquid working fluid 
in the vertically paralleled fin tubes absorbs heat stored in the liquid phase change medium in the cells outside the fin tubes and becomes boiled to produce a vapor working fluid which flows upward due to its buoyancy into the vertical low-temperature heat pipe. As heat is transferred to cold transporting fluid, the gaseous working fluid undergoes condensation on the outside of the fin tubes of the double pipe heat exchanger. Then the condensate flows along the wall of parallel tubes, absorbs heat from energy storage material, and becomes boiled to complete one cycle. The thermal energy storage device releases heat through the evaporation of working fluid inside vertical fin tubes and its condensation outside the fin tubes of double pipe heat exchanger.

The mechanism of simultaneous heat charge and discharge modes is initiated when there is thermal energy available for storage and heating load. In such an event, the thermal energy storage device can adjust the energy automatically based on the difference between available energy supply and load needs. If the thermal energy at the supply side is greater than the needs at the load side, the working fluid vaporized at the vertical plate tubes will partly condense into fluid and transfer energy to the double pipe heat exchanger. The remaining vapor will release excess heat to energy storage material through the vertical fin tubes in the storage tank. When the supply-side thermal energy is less than the heating load, the required load to heat the transporting fluid in the double pipe heat exchanger will be supplied simultaneously from high-temperature vertical plate tubes and energy storage material in the storage tank. If the supply-side thermal energy is equal to the heating load, the needs will be met directly by the supply-side thermal energy without drawing heat stored into the storage tank.

\section{EXPERIMENTAL INVESTIGATIONS}

As shown in Figure 2, the thermal energy storage device of this study features heat pipe characteristics of the two-phase closed loop and closed thermosyphon. It is comprised of a heating plate with vertical tubes, distributors, upper headers, fin tubes inside the energy storage tank, lower headers, and converge pipes. The upper headers also work as a double pipe heat exchanger during heat discharge. The energy storage tank contains two rows of fin tubes and has lower headers arranged at its bottom, which converge the working fluid in the fin tubes and send the fluid to the converge pipe at the lower end of the system where the fluid is uniformly distributed before it returns to the vertical pipe. Water is used as energy storage material in the storage tank and the working fluid inside the thermosyphon may be alcohol (i.e., ethyl alcohol for medicinal use, the degree of purity being $95 \%$ ) or water. The thermophysical properties of the working fluid at the boiling temperature are depicted in Table 1.

The heating section at the supply side of the heat source consisted of heating plates made of very thin foil heaters and ten vertical copper tubes. The energy storage tank was made of 3-mm thick stainless steel plates, in which two rows of fin tubes, 18 fins each, are mounted. Two headers each were connected at the top and bottom of the storage tank, where the two upper headers were copper tube sealed with cooper stoppers on both ends and contained internal stainless steel fins working as a double pipe heat exchanger during heat discharge. The use of double-row fins in the energy storage tank increases the heat transfer area during heat charge and discharge. A high specific-heat fluid was used as the energy storage material in the tank. Throughout the course of the experiment, heating plates at the supply side of the heat source and the exterior of the energy storage tank 


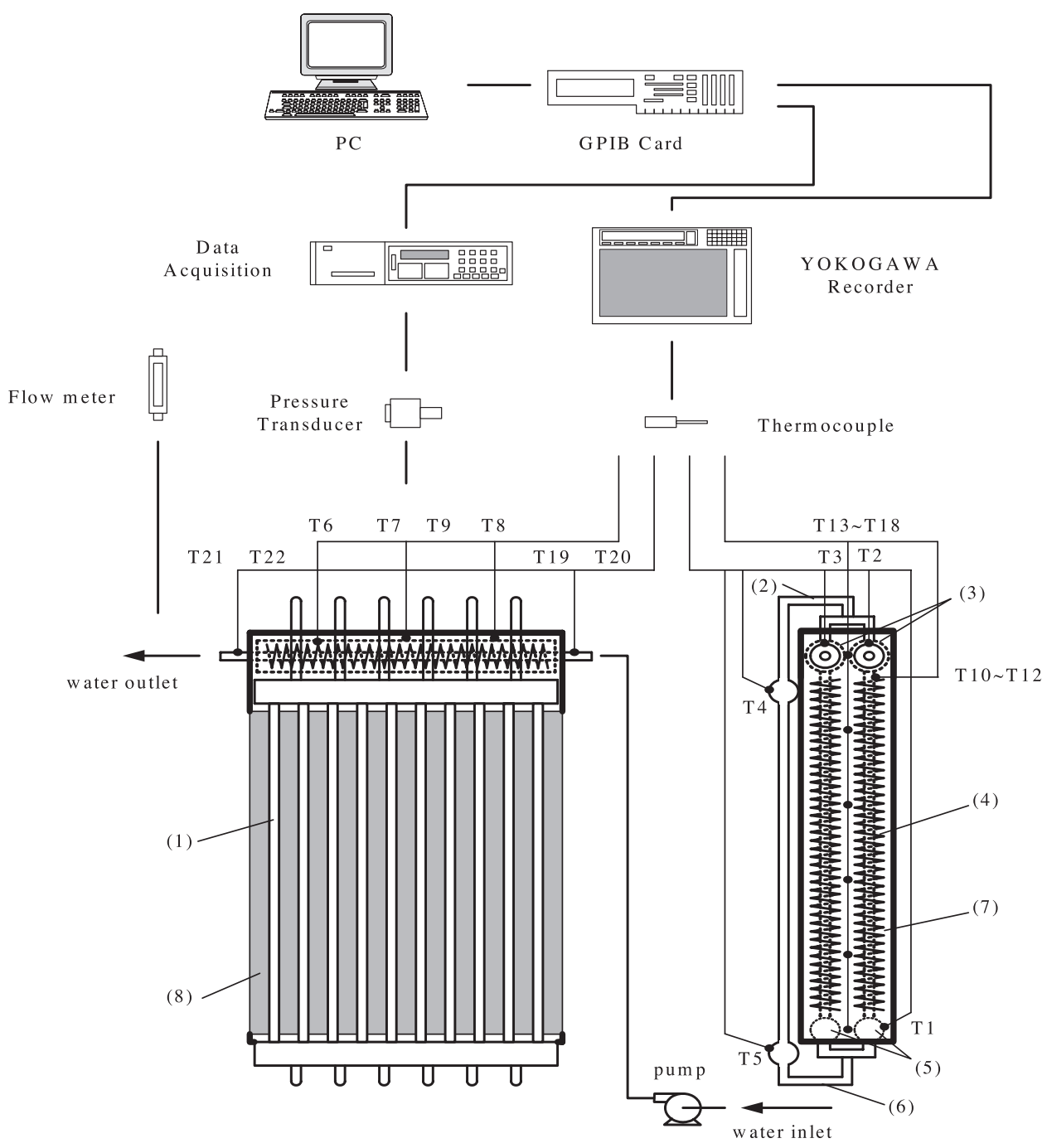

Figure 2. Experimental systems, equipment, and measurement systems: 1. tube, 2. distributor, 3. upper header, 4. fin tubes, 5. lower headers, 6. converge pipes, 7. energy storage tank, 8. heating plate.

were covered with insulation material to prevent heat loss resulting from temperature difference between the surroundings and the system. During the charge process, heat input was achieved by connecting the AC power supply to the foil heater; during heat discharge, heat output was carried out by adjusting the flow of water passing through the double pipe heat exchanger located at the top of storage tank.

Figure 3 is a schematic of measuring apparatuses used in the experiment for obtaining the physical quantity of primarily temperature and water flow, supplemented by data of pressure. Temperature measurement utilizes a T-type thermocouple with $0.3-\mathrm{mm}$ probe and recorder (YOKOGAWA HR2300). Temperature measurement points include 5 points (T1-T5) for temperature of working fluid inside the upper and lower headers of 
Table 1. Thermophysical properties of working fluid

\begin{tabular}{lll}
\hline \multicolumn{1}{c}{ Material } & Ethyl alcohol & Water \\
\hline Molecular formula & $\mathrm{C}_{2} \mathrm{H}_{6} \mathrm{O}$ & $\mathrm{H}_{2} \mathrm{O}$ \\
Boiling point $\left({ }^{\circ} \mathrm{C}\right)$ & 78.6 & 100 \\
Heat of evaporation $(\mathrm{kJ} / \mathrm{kg})$ & 847.0 & 2257 \\
Density $\left(\mathrm{kg} / \mathrm{m}^{3}\right)$ & & \\
$\quad$ Liquid & 735.4 & 1450 \\
$\quad$ Vapor & 1.866 & 1280 \\
Specific heat $(\mathrm{kJ} / \mathrm{kg}-\mathrm{K})$ & & \\
$\quad$ Liquid & 2.84 & 4.217 \\
$\quad$ Vapor & 1.61 & 2.029 \\
$\quad$ Thermal conductivity $(\mathrm{W} / \mathrm{m}-\mathrm{K})$ & & \\
$\quad$ Liquid & 0.164 & 0.680 \\
\hline
\end{tabular}

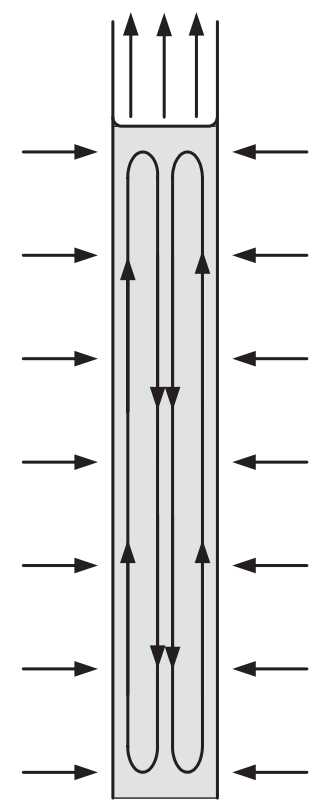

(a)

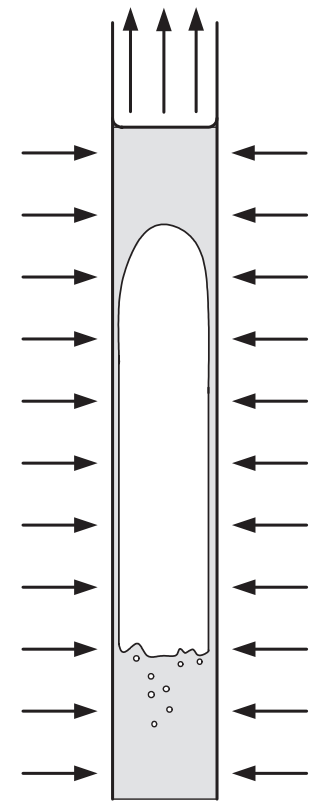

(b)

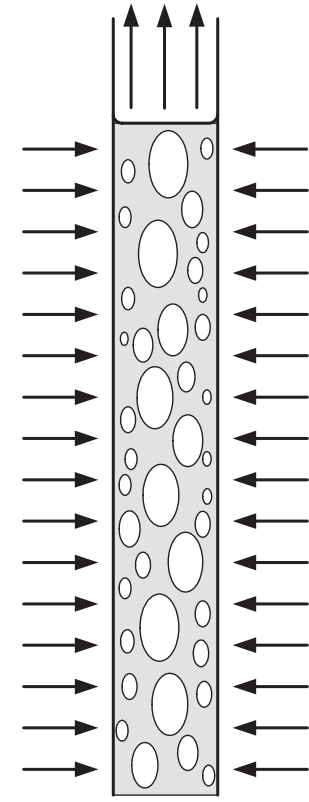

(c)

Figure 3. Flow patterns of boiling inside the vertical pipe: (a) natural convection, (b) geyser boiling, and (c) nucleate boiling.

the energy storage tank and the upper and lower connecting tubes at the supply side of the heat source, 4 points (T6-T9) on the walls of the upper header, 3 points (T10-T12) on the fins of the energy storage tank at different locations of the same level, 6 points (T13-T18) on the energy storage material, and 2 points each (T19-T22) at the inlet and outlet of the double pipe heat exchanger to measure the water temperatures with the total 22 points. 
The ratio of filling working fluid (fill ratio) in the thermal energy storage device, expressed by volume percentage, may be defined as follows:

$$
V_{f}=\frac{V_{r}}{V_{t}} \times 100 \%
$$

where $V_{r}=$ actual volume of working fluid charged and $V_{t}=$ total volume of the thermal energy storage device, which was $14,468 \mathrm{ml}$ by actual measurement. The fill ratio for this part of the experiment ranged between 35 and $60 \%$.

In this article, water is used as the energy storage medium. Only the sensible energy is stored or released during the charge mode and discharge mode. The heat is stored or released through sensible heat transfer mechanism. Therefore, stored heat of the system $Q_{c h}$ may be computed based on temperature rise of the energy storage material $\left(\Delta T_{i, j}\right)$ as shown in the following equation:

$$
Q_{c h}=\sum_{j=0}^{t} \sum_{i=1}^{6} M_{s} c_{p} \Delta T_{i, j}
$$

where $\Delta T_{i, j}=\left(T_{i, j+\Delta t}-T_{i, j}\right)$.

Discharged heat, $Q_{\text {dis }}$, may be obtained from the temperature drop of the energy storage material $\left(\Delta T_{i, j}\right)$ as shown in the following equation:

$$
Q_{d i s}=\sum_{j=0}^{t} \sum_{i=1}^{6} M_{s} c_{p} \Delta T_{i, j}
$$

Effective heat output, $Q_{\text {eff }}$, indicates thermal energy actually obtained from the energy input, which may be obtained from the temperature difference of cold water in the heat exchanger:

$$
Q_{e f f}=\sum_{j=0}^{t} \dot{m} c \Delta T_{w, j} \Delta t
$$

where $\Delta T_{w, j}=\left(T_{w, \text { out }}-T_{w, \text { in }}\right)$, time variance $\Delta t$ was $10 \mathrm{sec}$.

Two system-related efficiencies can be defined from Eqs. (2)-(4). The charge efficiency is the ratio of stored heat in energy storage material to heat input from power supply; the discharge efficiency is the ratio of effective absorbed heat of the double pipe heat exchanger to heat released from the energy storage material, which are expressed, respectively, as follows:

$$
\begin{gathered}
\eta_{c h}=\frac{Q_{c h}}{Q_{i n}} \\
\eta_{d i s}=\frac{Q_{e f f}}{Q_{d i s}}
\end{gathered}
$$

where heat supply, $Q_{\text {in }}$, is obtained from the product of electric input power and operating time:

$$
Q_{\text {in }}=P \cdot t_{o p}
$$


The heat flux input on heating plate could be defined as follows:

$$
q_{\text {in }}=\frac{Q_{\text {in }}}{A}
$$

Given that the system supplied and demanded energy at the same time under this operation mode, the computation of its energy variation requires some modification; system net energy variation, $Q_{\text {sys }}$, may be obtained from the following equation:

$$
Q_{s y s}=\sum_{j=0}^{t} \sum_{i=1}^{6} M_{s} c_{p} \Delta T_{i, j}
$$

\section{RESULTS AND DISCUSSION}

In the thermal energy storage device there are four fundamental transport processes, two of which involve phase change and two of which involve convection. Heat input to the evaporator transforms liquid to vapor. Vapor flows to the condenser. Cooling transforms this vapor back to liquid. Gravity then induces a liquid film to flow back to the evaporator. Charge and discharge processes in the thermal energy storage device characterize the feature of a two-phase closed loop thermosyphon (see Figure 1a) and a two-phase closed thermosyphon (see Figure 1b).

Flow patterns with different heat transfer mechanisms in the heating section of the thermal energy storage device during the charge process are demonstrated in Figure 3. As the heating power applied on the vertical plate tubes is increasing, three different flow patterns including natural convection, geyser boiling, and nucleate boiling are observed in the evaporator. When the heating power is low, the temperature of working fluid gradually increases due to natural convection. In this period, the heat transfer is the lowest. As the heating power becomes larger, periodic large slug forms inside the tubes and oscillates violently. The heat transfer mechanism of this flow pattern is geyser boiling. Geyser boiling is a complex heat transfer mechanism with period oscillation in vapor temperature. Seki et al. [9], Kuncoro et al. [10], and Lin et al. [11] studied the heat transfer mechanism of geyser boiling in a two-phase closed thermosyphon. Casarosa et al. [12] developed correlations to identify nucleate boiling and geyser boiling from the bubble frequency and study the heat transfer mechanism of geyser boiling. Furthermore, Niro and Beretta [13] constructed a boiling regime map for a two-phase closed thermosyphon.

When the heat flux is getting higher, the bubbles become small and increase continuously. This phenomenon could be considered as the nucleate boiling. The heat transfer coefficient of nucleate boiling is the highest in the charge process. This phenomenon can be demonstrated from the experiment, which uses alcohol as working fluid under $40 \%$ of the fill ratio and different heat flux to undergo heat storage. The result of this experiment is illustrated in Figure 4, which shows the gas temperature histories of working fluid. Something interesting could be inferred from this T4 measurement. At the lowest heat flux $\left(100 \mathrm{~W} / \mathrm{m}^{2}\right)$, the heat transfer mechanism in working fluid has only undergone a natural convection process. When the heat flux is between 200 and $800 \mathrm{~W} / \mathrm{m}^{2}$, the vapor oscillation will occur. It is obvious that the greater the heat flux, the larger oscillation frequency in vapor temperature. However, the amplitude of temperature pulse becomes 


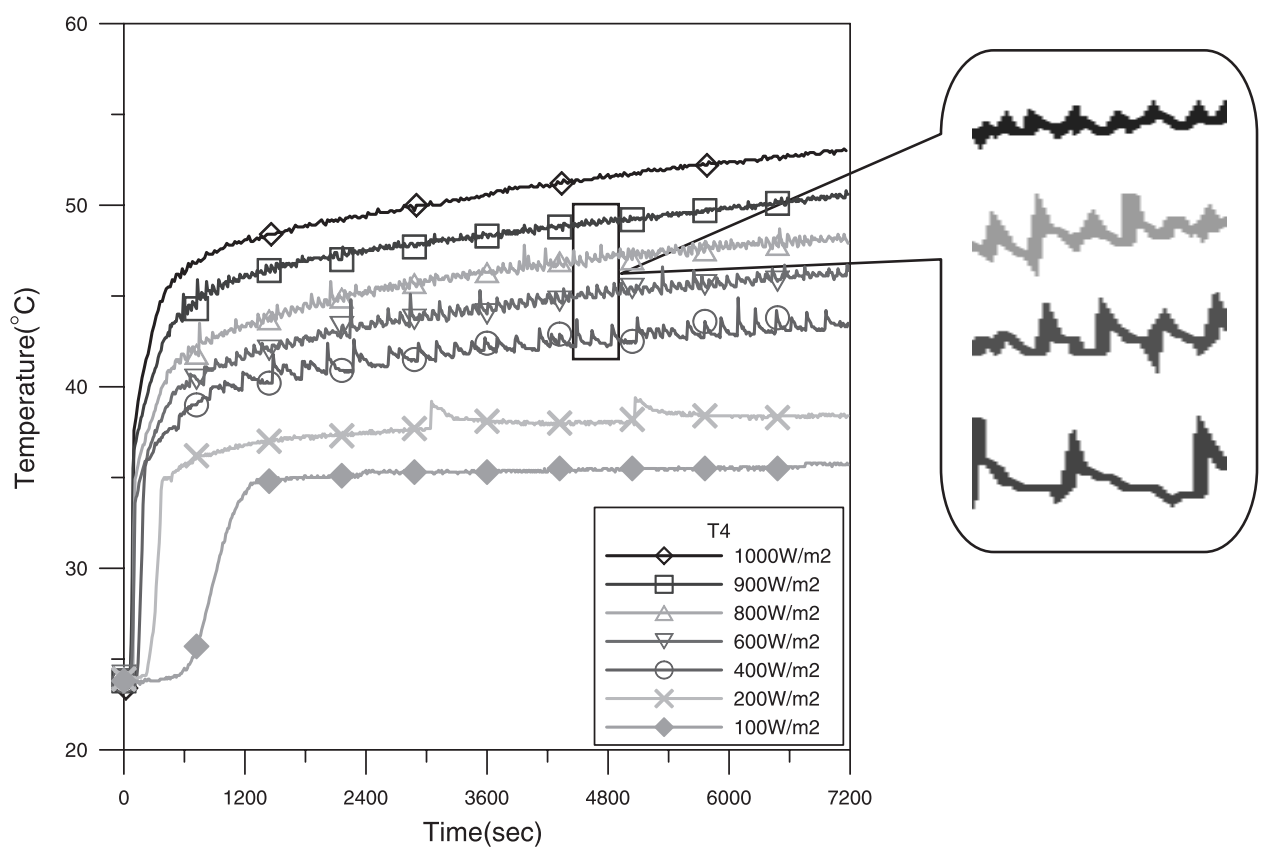

Figure 4. Gas temperature histories of working fluid (alcohol) with different heat flux.

smaller in the higher heat flux. Until the heat flux is large enough (above $800 \mathrm{~W} / \mathrm{m}^{2}$ ), the working fluid inside the vertical pipe would be experiencing the nucleate boiling process.

During the charge process within the thermal energy storage device, most of the time the condensate forms a liquid film in the cooling section, which due to gravity, flows downward toward the liquid and back to the evaporator. As shown in Figure 1a, a continuous supply of downwardly flowing vapor replenishes the liquid film by condensing due to the removal of thermal energy to the energy storage material in the storage tank. The resulting co-current, annular, two-phase flow exists inside the condenser. Film condensation is the dominated heat transfer mechanism in the cooling section of the thermal energy storage device during the charge process.

During the discharge process, as shown in Figure 1b, several evaporation mechanisms are occurring simultaneously in the heating section of the thermal energy storage device, the most important of which are: boiling of liquid pool and evaporation of the condensate returning along the tube wall. Depending on the heat flux, boiling in the liquid pool will either be nucleate boiling (at heavy thermal load) or natural convection (at light thermal load). The heat transfer processes of the falling liquid film can be observed as a smooth or wavy film with surface evaporation. Figure $1 \mathrm{~b}$ also shows that in the cooling section at the top of thermal energy storage device, film-wise condensation occurs along the fin tubes at the double pipe heat exchanger. Due to gravity, the condensate will flow back to the heating section.

The thermal energy storage device undergoes the cycle of heat absorption and release through passage of working fluid in the heating (evaporation) and cooling (condensation) section. The choice of working fluid has a significant influence on the thermal 


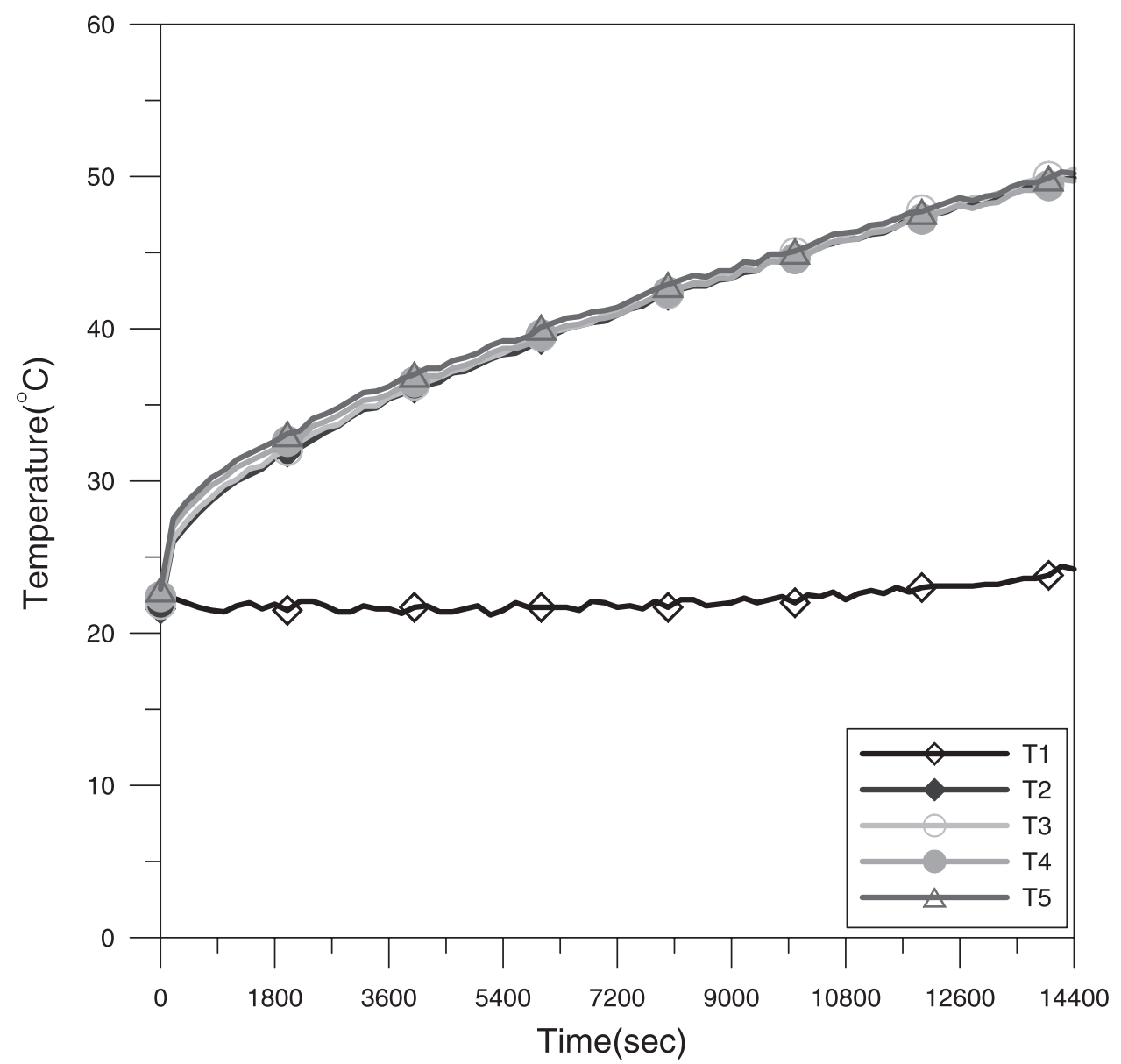

Figure 5. The temperature variation of working fluid (alcohol) during heat charge process.

performance. In addition, the fill ratio of working fluid is also an important parameter of system performance. The operating conditions for this part of the experiment were: $35-60 \%$ fill ratio, alcohol and water as working fluid, $1,300 \mathrm{~W} / \mathrm{m}^{2}$ of heat flux to undergo 4 hours of heat charge, and in case of heat discharge, a water flow rate at 3 LPM to undergo 2 hours of discharge. The results of this experiment are illustrated in Figures 5-9.

The results of the experiment which uses alcohol as working fluid under $40 \%$ fill ratio are shown in Figures 5-7. Figure 5 depicts temperature variation of working fluid during heat charge. The temperature of the liquid working fluid (T1) displays the lowest among these five points. It is the reason that the liquid working fluid, which undergoes condensing for releasing the heat to energy storage material, will return to the evaporation side to absorb the heat from heat flux on the heating plate. Furthermore, the other four temperatures (T2-T5) are approximately equal, meaning the vapor working fluid could delivery thermal heat from the evaporation side to the condensation side fast and uniformly. Temperature variation of the heating plate and energy storage material 


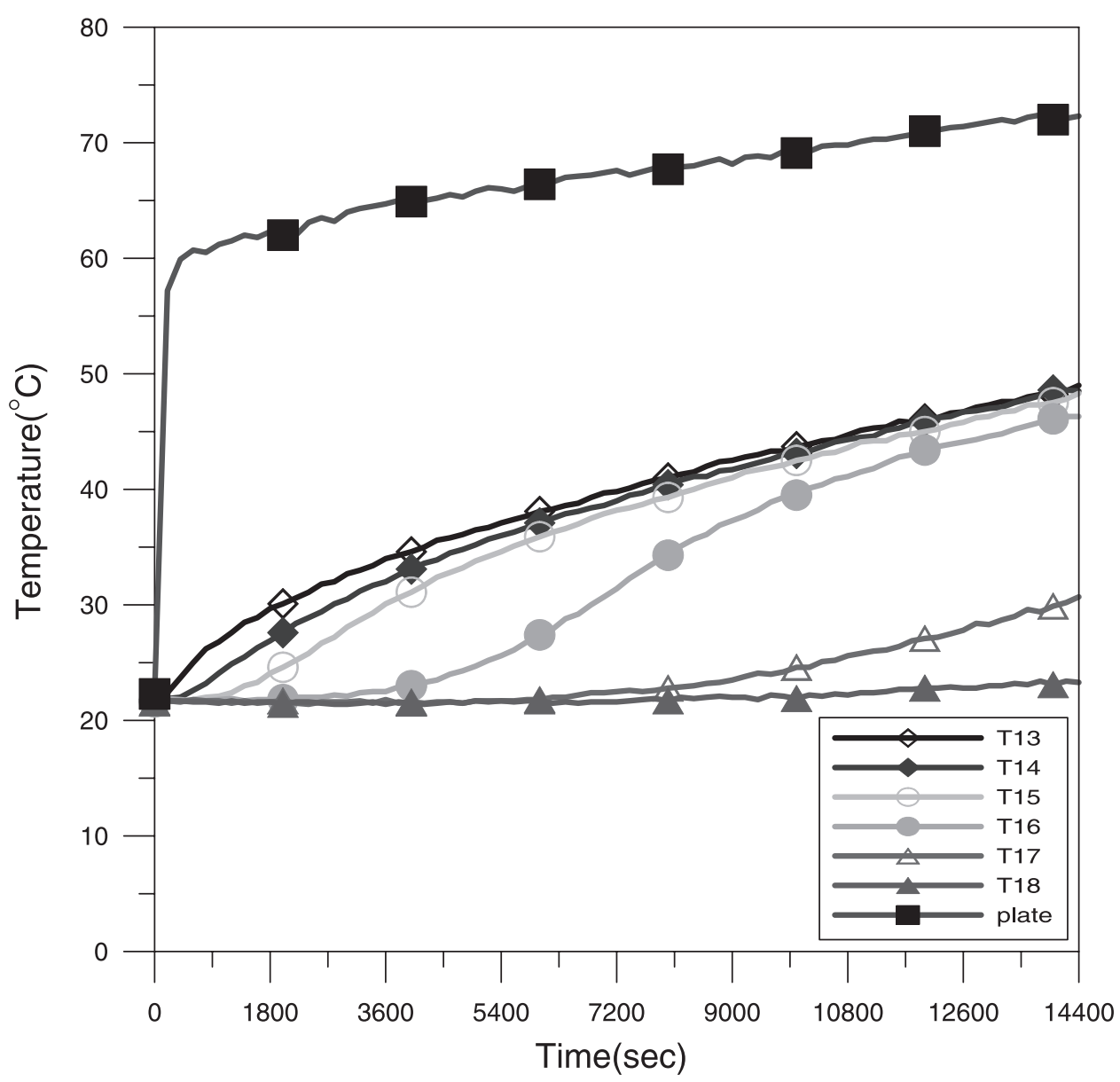

Figure 6. The temperature variation of heating plate and energy storage material (water) inside storage tank during heat charge process.

during heat storage is illustrated in Figure 6. Of the six measurement points (T13-T18), the energy storage material near the upper and lower header exhibited the highest and lowest temperature, respectively, while four points in the middle were evenly distributed. It is also observed that the energy storage material displayed mild thermal stratification where heat storage was satisfactory from $\mathrm{T} 13$ to T16, but not as desirable at the lower points, i.e., T17 and T18.

In the sensible heat storage system, the thermal stratification will occur due to the density disparity of the energy storage material. In the present study, at the higher fill ratio conditions, the length of effective condenser section inside the two-phase closed loop thermosyphon becomes shorter. Therefore, the energy storage material at the upper region inside the storage tank will absorb more thermal energy than the lower region, which causes a larger temperature difference between the upper and lower regions. However, in the present study, it is found that there exists an optimal fill ratio of working fluid in this energy storage system. Under this condition, the temperature difference of the 


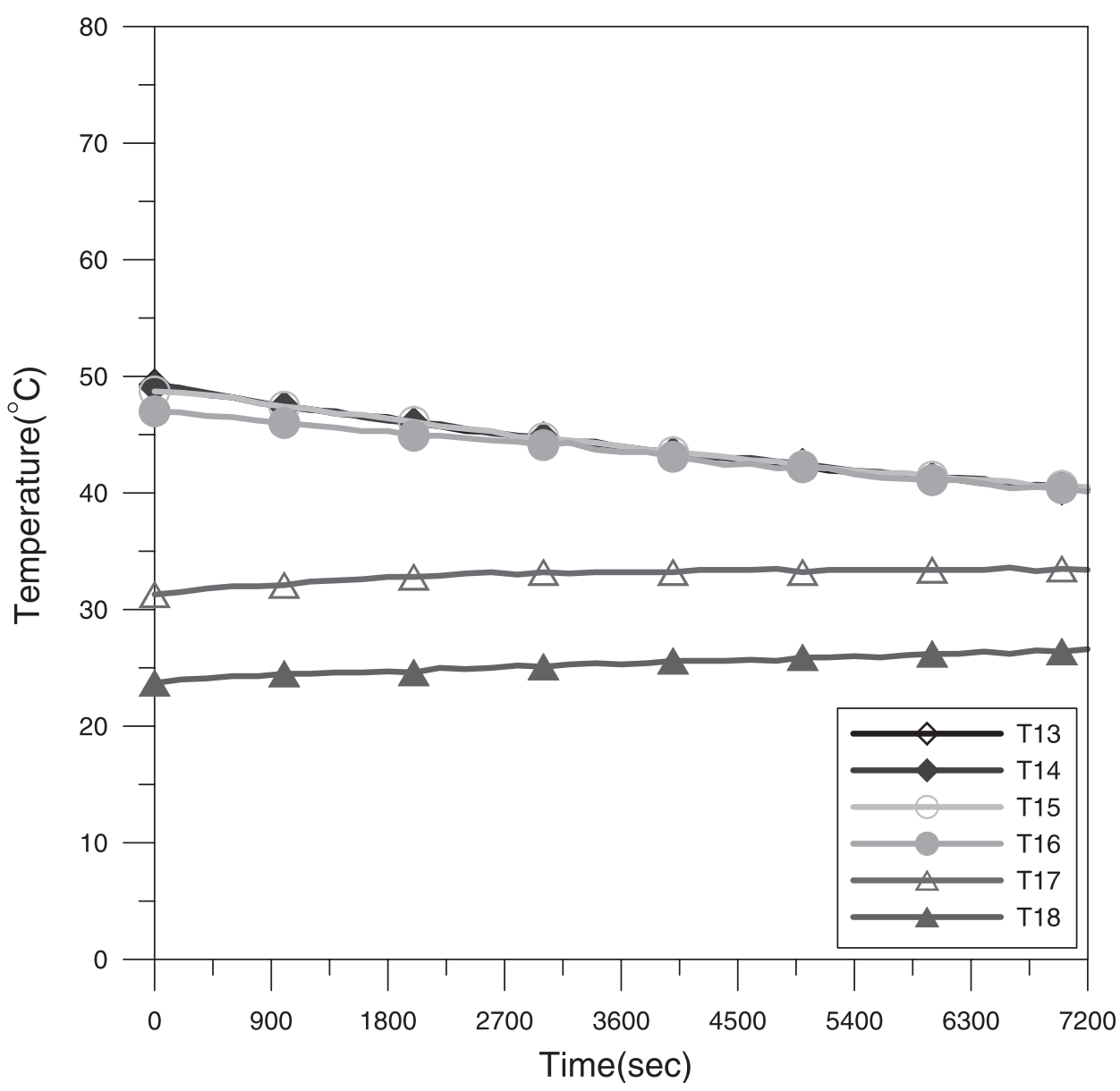

Figure 7. The temperature variation of energy storage material (water) inside storage tank during heat discharge process.

energy storage material is small and the stored thermal energy is large. The thermal stratification in this energy storage system is not so serious as compared with the normal heat storage. Figure 7 depicts the temperature variation of the energy storage material in the storage tank during heat discharge. Same as with the time of heat storage, the energy storage material also displayed thermal stratification during heat discharge, only the small temperature variation in the first four measurement points (T13-T16) were consistent, suggesting system stability.

Figure 8 displays the variation of charge efficiency under different working fluids and fill ratios. As shown, the system had better charge efficiency with alcohol as the working fluid and the highest storage efficiency of $73 \%$ is obtained at $40 \%$ fill ratio; with water as the working fluid, the system exhibits better storage efficiency at fill ratios ranging from $40-50 \%$. Under the higher fill ratio condition, the condensation effect of working fluid is poor due to the short length of the condenser, in spite of the working fluid inside the heating plate transferring more thermal heat to the energy storage material. 


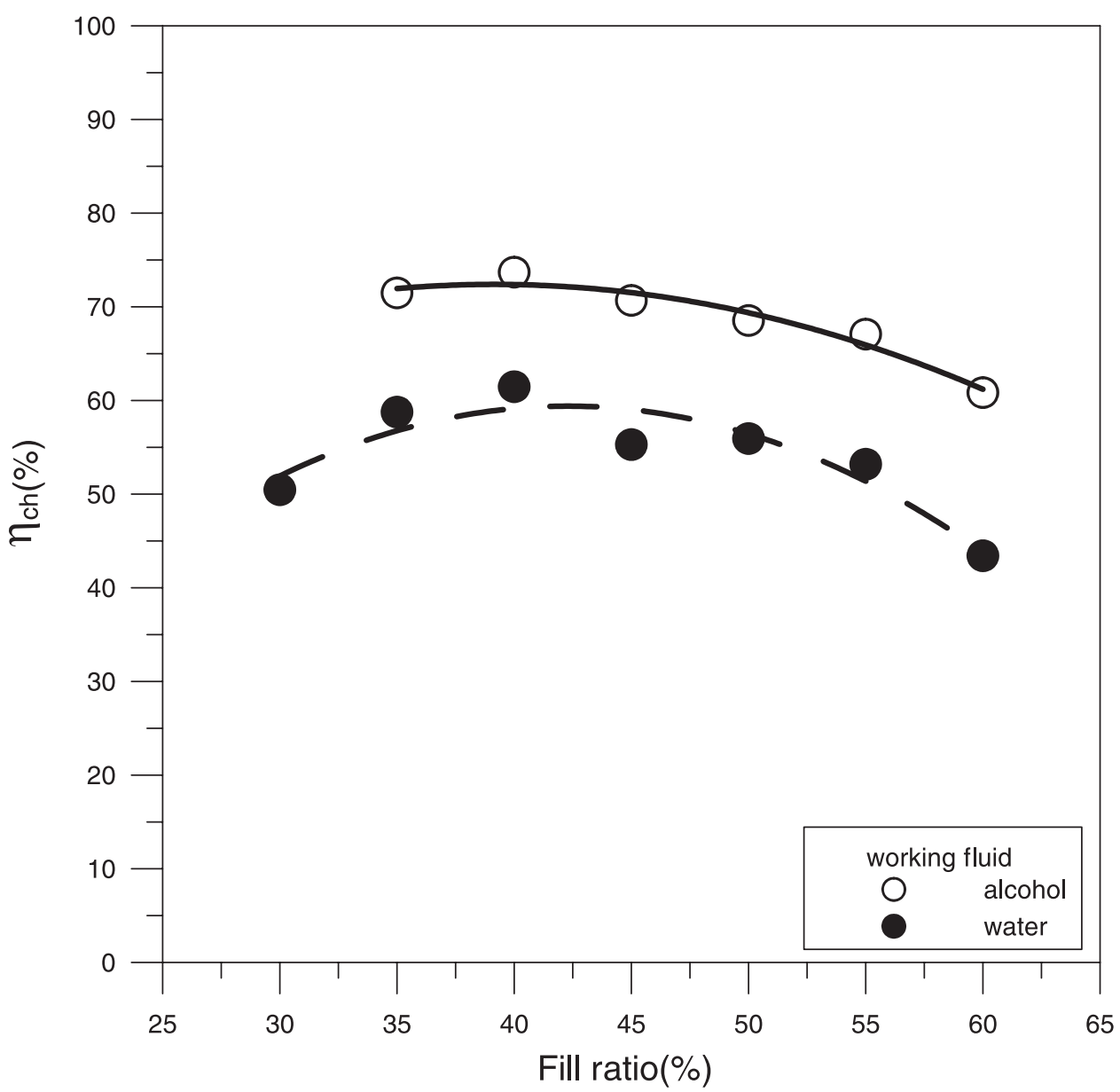

Figure 8. Comparison of the heat charge efficiency under different working fluid and fill ratio.

Therefore, there exists an optimal fill ratio to maximize the stored heat of the system. Figure 9 indicates that discharge efficiency with alcohol as the working fluid near the linear drop has its highest discharge efficiency of $85 \%$ at $35 \%$ fill ratio. With water as the working fluid, the discharge efficiency was better at fill ratios between 35 and $45 \%$.

As shown in Figures 8 and 9, alcohol generally performs better than water. It should be noted that water and alcohol were chosen as the working fluids, since they are compatible with copper and are safe materials with which to work. Due to the different thermal characteristics between alcohol and water, different performances occurred with them. The boiling temperature of water and alcohol at atmospheric pressure is 100 and $78.6{ }^{\circ} \mathrm{C}$, respectively. The latent heat of evaporation is $2258 \mathrm{~kJ} / \mathrm{kg}-\mathrm{K}$ for water and $847 \mathrm{~kJ} / \mathrm{kg}-\mathrm{K}$ for alcohol. Due to the smaller latent heat of alcohol, the mass flow rate of vapor at the evaporation section is larger than that of water at the same thermal heat input. The response time of thermal storage for alcohol is faster than that of water, therefore, it is the recommended working fluid for the thermal energy storage device. 


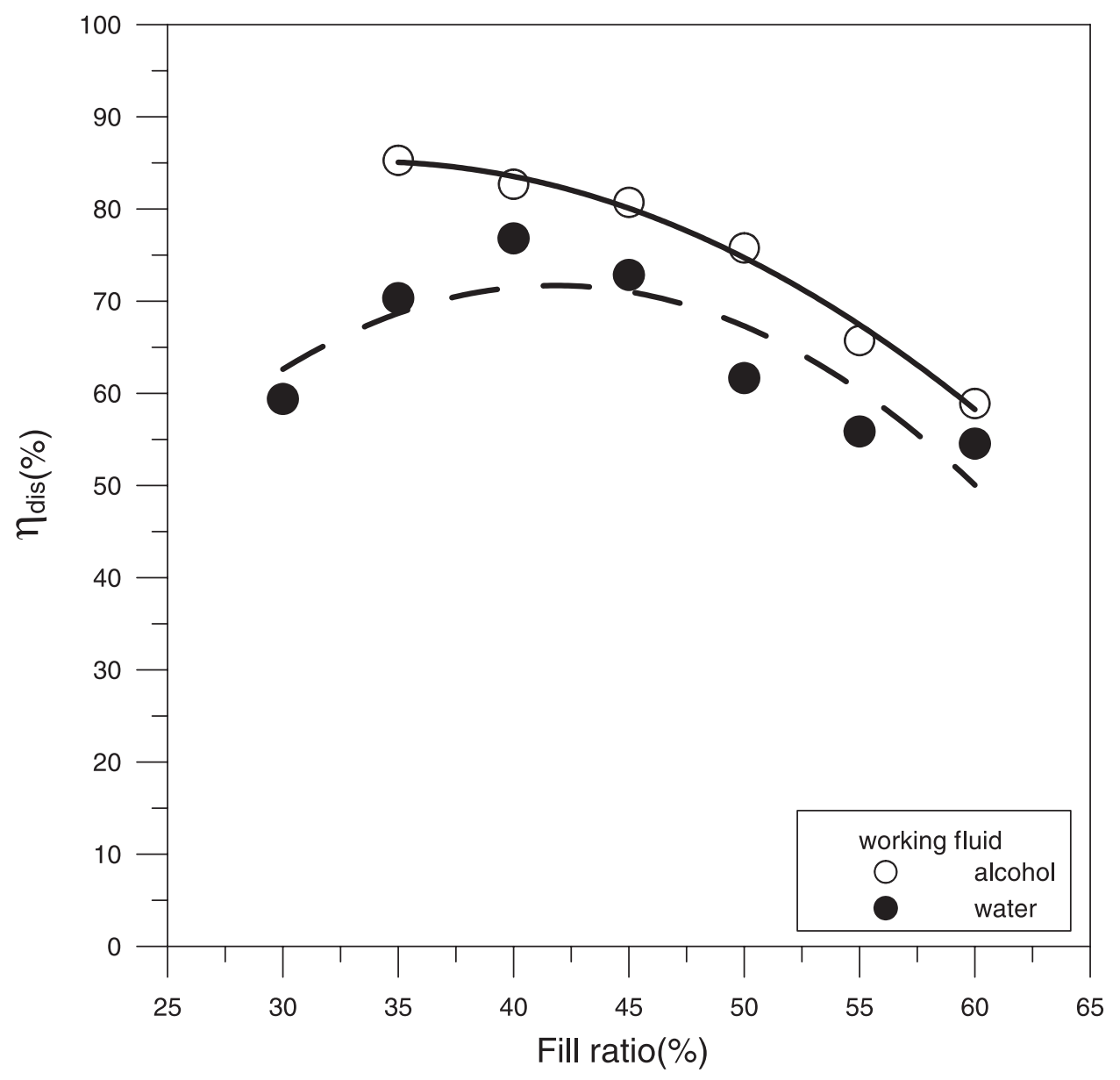

Figure 9. Comparison of the heat discharge efficiency under different working fluid and fill ratio.

The thermal energy storage device can also undergo simultaneous charge and discharge processes. The operating conditions for this experiment were: $40 \%$ fill ratio, alcohol as working fluid, $1,300 \mathrm{~W} / \mathrm{m}^{2}$ of heat flux to undergo heat storage, and water flow rate at 1.4 and 5 LPM to undergo discharge. The operation in this experiment had two stages: in the first 5,400 seconds (1.5 hours), thermal energy was transferred from the heat source to the energy storage material and double pipe heat exchanger at a high flow rate of $5 \mathrm{LPM}$; in the second 5,400 seconds, thermal energy was transferred from the heat source and energy storage material to the double pipe heat exchanger at a low water flow rate of 1.4 LPM. Figure 10 provides supplemental information. It is seen that when the heating load (under a high flow rate, i.e., 5 LPM) was greater than the heat supply, the stored energy in the energy storage material dropped to make up the deficiency; when the heat supply was greater than the heating load (under a low flow rate, i.e., 1.4 LPM), the energy storage material stored excess heat in the storage tank, boosting the stored energy in the tank, thus indicating that the system did have the anticipated function of automatic adjustment. 


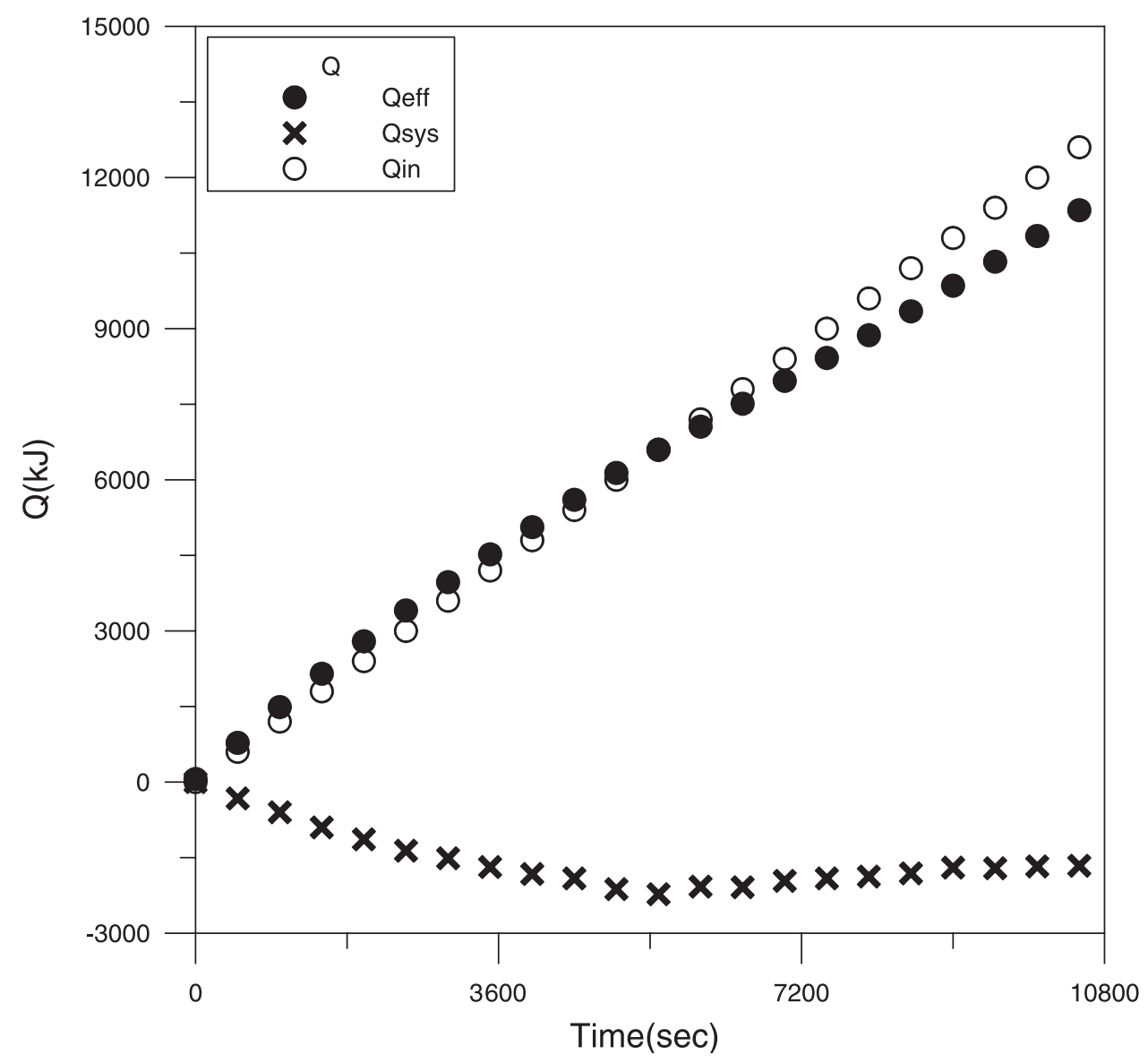

Figure 10. The variation of each heat on simultaneous heat storage and heat discharge.

\section{CONCLUSION}

Three heat transfer mechanisms are identified in the evaporation sides of a thermal energy storage device during the charge mode. At a lower heat flux (below $100 \mathrm{~W} / \mathrm{m}^{2}$ ), the heat transfer mechanism is only natural convection. When the heat flux is between 200 and $800 \mathrm{~W} / \mathrm{m}^{2}$, the geyser boiling occurs. At a larger heat flux (above $800 \mathrm{~W} / \mathrm{m}^{2}$ ), the nucleate boiling becomes the dominated heat transfer mechanism with the best heat transfer coefficient. Under the operating conditions of this study, the proper range is $35-40 \%$. The system performs better with alcohol as the working fluid. As verified empirically, the thermal energy storage device performs three functions: simple heat storage, simple heat discharge, and simultaneous heat storage and discharge.

\section{REFERENCES}

1. Z. Lavan and J. Thompson. Experimental Study of a Thermally Stratified Hot Water Storage Tanks, Solar Energy, vol. 19, no. 5, pp. 519-524, 1977. 
2. M. A. Abdoly and D. Rapp. Theoretical and Experimental Studies of Stratified Thermocline Storage of Hot Water, Energy Conversion and Management, vol. 22, no. 3, pp. 275-285, 1982.

3. F. J. Oppel, A. J. Ghajar, and P. M. Moretti. A Numerical and Experimental Study of Stratified Thermal Storage, Transactions of ASHRAE, vol. 92, pp. 293-309, 1986.

4. R. S. Misra. Thermal Stratification with Thermosyphon Effect in Solar Water Heating Systems, Energy Conversion and Management, vol. 35, no. 3, pp. 193-203, 1994.

5. I. Dincer. On Thermal Energy Storage Systems and Applications in Buildings, Energy and Buildings, vol. 34, pp. 377-388, 2002.

6. A. Biyikoglu. Optimization of a Sensible Heat Cascade Energy Storage by Lumped Model, Energy Conversion and Management, vol. 43, pp. 617-637, 2002.

7. Z. Pluta and W. Pomierny. The Theoretical and Experimental Investigation of the Phase-Change Solar Thermosyphon, Renewable Energy, vol. 6, no. 3, pp. 317-321, 1995.

8. N. Ghaddar and Y. Nasr. Experimental Study of a Refrigerant Charged Solar Collector, International Journal of Energy Res., vol. 22, no. 7, pp. 625-638, 1998.

9. N. Seki, S. Fukusako, and K. Koguchi. An Experimental Investigation of Boiling Heat Transfer of Fluorocarbon R11 Refrigerant for Concentric Tube Thermosyphon, Journal of Heat Transfer, Transactions of ASME, vol. 103, no. 3, pp. 472-477, 1981.

10. H. Kuncoro, Y. F. Rao, and K. Fukuda. An Experimental Study on the Mechanism of Geysering in a Closed Two-phase Thermosyphon, International Journal of Multiphase Flow, vol. 21, no. 6, pp. 1243-1252, 1995.

11. T. F. Lin, W. T. Lin, Y. L. Tsay, and J. C. Wu. Experimental Investigation of Geyser Boiling in an Annular Two-phase Closed Thermosyphon, International Journal of Heat Mass Transfer, vol. 38 , no. 2, pp. 295-307, 1995.

12. C. Casarosa, E. Latrofa, and A. Shelginski. The Geyser Effect in a Two-Phase Thermosyphon, International Journal of Heat Transfer, vol. 26, no. 6, pp. 933-994, 1983.

13. A. Niro and G. P. Beretta. Boiling Regimes in a Closed Two-Phase Thermosyphon, International Journal of Heat Mass Transfer, vol. 33, no. 10, pp. 2099-2110, 1990. 